\title{
Question Order and Multidimensionality of Partisanship*
}

\author{
Michael A. Maggiotto, Bowling Green State University \\ Gary D. Wekkin, University of Central Arkansas
}

The recognition of question-order problems has prompted a reexamination of theory and data in several areas of political behavior. The possibility of question-order effects is of special concem to the study of party identification, the original conceptualization of which has been criticized for disregarding multi dimensionality. We have yet to discover whether the sequence and/or proximity of items measuring multiple, related dimensions may influence findings.

An area of research in which results may be especially susceptible to reactivity is that of multiple partisan identification. Most of the studies in this literature asked respondents a context-differentiated sequence of items about their partisan identification in national and state and (infrequently) local politics, respectively, separated only by the usual probes for intensity and direction. The responses obtained logically risk contamination by either consistency or contrast effects, as well as by salience or frame-ofreference effects generated by intervening or antecedent, nonrecursively-related items.

In this study, we report the results of two experiments used to control for potential question-order effects in the measurement of multiple party identification. In the first, national and state partisan identification items were altemated in sequence in order to test whether responses to national partisan identification items structure responses to state (and local) partisan identification items. In the second, party thermometer items, national, state, and local partisan identification items, and national, state, and local retrospective evaluations of party goveming performance were rotated sequentially. Generally, responses to these three measures of partisanship did not differ significantly as the order of appearance changed.

\section{Introduction}

Recent survey research has uncovered much about the manner in which question order may influence findings sufficiently to compete with substantive explanations of those findings. Bishop (1990) and Bishop, Oldendick and Tuchfarber $[1982,1984]$ pointed to changes in question order and context to account for much of the precipitous decline in political interest recorded in NES studies. Abramson, Silver and Anderson [1987] concluded that a change of question order helped to cause a 16 percent decline observed between 1980 and 1984 in agreement with one of the NES citizen-duty items. Schuman and Presser [1981] recount numerous other instances in which question order changes appear to have contaminated responses to attitudinal questions and present a typology of question order effects that may influence substantive findings. Among these are effects that occur when responses to items are adjusted either to be consistent with (consistency effect) or independent of (contrast effect) responses to earlier, related items, and when the response to an item is conditioned either by the context of several preceding, related items (salience effect) or by the lack of such points for comparison (frame-of-reference effect).

The Midsouth Political Science Journal, Vol. 13, Winter 1992: 501-514

CMidsouth Political Science Joumal 
Central in this literature is an ongoing debate about the reactivity of questionnaire items to each other. Sears and Lau (1983) view the observed relationships between personal financial situation and electoral choice in several data sets as methodological artifacts (viz., consistency effects termed personalization and politicization, respectively) produced by the proximity of these items to each other. Such effects are most likely when items are (1) adjacent, (2) interrelated, and/or (3) conceptually amorphous. Lewis-Beck (1985) countered that, in NES studies, at least, the responses to these two items did not covary with the distance (measured as the number of intervening items) between them. Lau, Sears and Jessor (1990) rejoin that although reactivity is less of a concern as proximity gives way to distance, it remains a problem for items in close sequence, is more likely when the items hypothesized to be dependent effects are subjective judgments with an inherent potential for reactivity, and may be reinforced by the relatedness of intervening items.

Such question order effects especially concern students of party identification. Not only are multiple questions necessary to establish the measurement of party identification (Campbell et al.1960) --thus inviting the presence of interrelatedness and proximity which may conduce to reactivity -- but the dimensionality of that measurement is open to question (Katz 1979; Maggiotto and Piereson 1977; Petrocik 1974; Valentine and Van Wingen 1980; Weisberg 1980, 1983). Moreover, multiple conceptions of the phenomenon exist. For example, Fiorina (1981) presents convincing evidence of the value of viewing partisanship not as psychological affect but as retrospective policy evaluation, causing another battery of questions -- subjective judgments different than, yet related to partisan identification -- to be included. Still others have demonstrated the non-recursive effects of electoral choice on partisanship (Markus and Converse 1979; Franklin 1984; Franklin and Jackson 1983; Page and Jones 1979), a result that conceivably may stem from the order and proximity in which these related behaviors and attitudes appeared.

The degree to which any of these partisan findings stem from the placement of questions in surveys is unknown. However, given the literature cited above, it is reasonable to expect that multiple, related items more or less proximate to each other may not be immune to order and context contamination.

One area of partisan research in which findings may be especially susceptible to question order effects is the new field of segmented or multiple party identification. Recently several studies have measured whether voters, especially in the South, report different partisan identifications for different (national, state, and local) levels of government within the American federal system (Jennings and Niemi 1966; Hadley 1985; Maggiotto 1986; Maggiotto and Wekkin 1987, 1989; Niemi, Powell and Wright 1987; Wekkin 1991). These studies asked respondents a sequence of two or more partisan items to measure their orientation toward national, state, and local partisanship, respectively. To what extent might the responses obtained for the second and third questions in this sequence be altered by consistency or contrast effects? Might other, preceding items nonrecursively 
related to partisanship (e.g., candidate choice or ideology) result in salience effects? Is it possible that, as some (Jennings and Niemi 1966; Hadley 1985) suggest, one's national party identification has a salience effect in that it structures one's partisanship at the other levels of the polity as well? These are effects that could contaminate the new literature on segmented partisanship, as well as the standard and revisionist literature on partisanship. As such, these effects should be candidates for empirical analysis.

\section{Methodology and Measures}

The purpose of this paper is to report the results of experiments that controlled for consistency, contrast, salience, and frame-of-reference effects in studies of segmented partisanship. The data are drawn from two successive surveys of Arkansas' Second Congressional District. ${ }^{1}$ In the first survey, exit interviews were given to 402 systematically-selected voters in 17 randomly selected precincts on general election day, November 4, 1986. These voters were asked to respond to national, state, and local-specific variations of the standard NES party identification question. ${ }^{2}$ The order in which the national and state party identification items appeared was alternated in every other questionnaire, in order to test for consistency and contrast effects, as well as for the salience of the national party identification item.

The second survey consisted of exit interviews with 576 systematicallyselected voters in the same precincts (plus two) on "Super Tuesday," March 8, 1988. This time a more complex experiment was performed in order to control for more conventional salience effects, as well as for consistency and contrast. Specifically, the same national, state, and local adaptations of the NES partisan identification question were used, complemented by national, state, and local variations of an item measuring voters' retrospective evaluations of party governing performance, and by a thermometer-scale measurement of global (not federally differentiated) partisan affect. Each of these operationalizations was buffered from the others by measures of different (but not always unrelated) attitudes and behaviors, and was rotated in sequence on each successive questionnaire. (See Appendix for exact wording and formatting.) Thus, the data used here should provide a good test of reactivity in the presence of proximity, subjectivity, and the interrelatedness of measures.

Since the design was intended primarily to measure segmented partisanship rather than to study question-order effects, it was decided that the various operationalizations of partisanship should be separated by as many items as possible in order to minimize the likelihood of consistency and contrast effects. Thus, the existence of salience effects may be indicated or contra-indicated in our findings below, but item-specific contributions to these effects are too difficult to estimate. 


\section{Question Order and the Measurement of Multiple Party Identification}

Discovering whether the order in which segmented partisanship items affected the incidence of multiple partisanship was of primary concern to the broader project. Therefore, we rotated the order in which the national and state party identification questions were asked respondents on each successive interview. Ideally, the rotation should have included local identification, but we were concerned with diminishing cell sizes in the experiment. The results of experimenting with the placement of national and state partisanship questions are contained in Table 1.

Table 1. The Distribution of Global and Multiple Identifiers by Question Order

\begin{tabular}{lccc}
\hline & $\begin{array}{c}\text { National ID } \\
\text { First }\end{array}$ & $\begin{array}{c}\text { State ID } \\
\text { First }\end{array}$ & $\begin{array}{c}\text { Row } \\
\text { Total }\end{array}$ \\
\hline $\begin{array}{l}\text { Segmented Partisans } \\
\text { Global Partisans }\end{array}$ & $21.5 \%$ & $26.9 \%$ & $24.1 \%$ \\
$\mathrm{~N}=$ & 78.5 & 73.1 & 75.9 \\
\hline
\end{tabular}

The row marginals in Table 1 reveal that approximately 24 percent of the 1986 sample were multiple partisans, across three levels of government, and the remaining 76 percent were global partisans. The Chi-square significance level, .26 , indicates that observed cell frequencies do not deviate significantly from the expected frequencies, given the row and column marginals. Though insignificant, there is a slight tendency for there to be more multiple identifiers when state partisanship is asked first. Thus we felt it prudent to look further at the distribution of partisanship at each level of government, in Table 2.

The second phase of the experiment revealed no significant variation in distribution of national, state, and local party identifiers, regardless of whether national or state partisanship was asked first. The percentage of respondents who regarded themselves as Democrats was somewhat higher, as one moved from national to state to local identification $(0.4,5.3$, and 10.8 percent, respectively), among those who were quizzed about their party preference in state politics first. From the same perspective, among Republican identifiers, the differences were markedly smaller and in the opposite direction $(3.0,1.5$, and 0.0 percent, respectively). Independent identifiers revealed a third pattern, being somewhat more numerous when national identification was asked first.

Consistent with the small and inconsistent differences noted above, a loglinear analysis in Table 3 of the crosstabulation of each party identification question by question order failed to reject the null hypothesis (at the .05 level) that no significant interaction existed between partisanship and question sequence. 
This definitive test (Feinberg 1977) contradicts the expectations of Jennings and Niemi (1966) and of Hadley (1985): responses to national party identification items do not structure responses to state (or, inferentially, to local) party identification items that follow in close sequence.

Table 2. The Distribution of Level Segmented Party Identification Within Experimental Groups Defined by Question Order

Panel 1: National Party Idenifification

$\begin{array}{lcc} & \text { National ID } & \text { State ID } \\ & \text { First } & \text { First } \\ \text { Democrats } & & \\ \text { Independents } & 56.1 \% & 56.5 \% \\ \text { Republicans } & 56.1 \% & 56.5 \% \\ \text { Other } & 15.1 & 13.1 \\ & 26.3 & 29.3 \\ \mathrm{~N}= & 2.4 & 1.0\end{array}$

Chi-Square $=.76$

Panel 2: State Party Identification

National ID

State ID

First

First

$\begin{array}{lcc}\text { Democrats } & 60.5 \% & 65.8 \% \\ \text { Independents } & 18.0 & 12.1 \\ \text { Republicans } & 19.0 & 20.5 \\ \text { Other } & 2.4 & 1.6 \\ \mathrm{~N}= & 205 & 190\end{array}$

Chi-Square $=.58$

Panel 3: Local Party Identification

$\begin{array}{cc}\text { National ID } & \text { State ID } \\ \text { First } & \text { First }\end{array}$

$\begin{array}{lcc}\text { Democrats } & 52.5 \% & 63.3 \% \\ \text { Independents } & 28.5 & 18.6 \\ \text { Republicans } & 16.0 & 16.0 \\ \text { Other } & 3.0 & 2.1 \\ \mathrm{~N}= & 200 & 188\end{array}$

Chi-Square $=.23$ 
Table 3. A Loglinear Analysis of Consistency Effects on Segmented Partisanship Questions

\begin{tabular}{lcc}
\hline Partisanship & $\begin{array}{l}\text { Likelihood Ratio } \\
\text { Chi-Square* }\end{array}$ & N \\
\hline National Identification & .729 & 394 \\
State Identification & .263 & 392 \\
Local Identification & .119 & 384 \\
& & \\
\hline
\end{tabular}

${ }^{*} \mathrm{p} \leq .05$

\section{Question Order and Multiple Operationalizations of Partisanship}

The 1988 experiment tested whether the placement of questions in a survey significantly alters results when two or more operationalizations are used to measure partisanship within the same interview. To investigate this problem, we rotated the placement of segmented party identification, multiple retrospective evaluation, and party thermometer items in the three formats indicated in Table 4 below:

Table 4. Questionnaire Formats

\begin{tabular}{lll}
\hline Format 1 & Format 2 & Format 3 \\
\hline party thermometer & retro. eval of party & seg. party ID \\
ideology & ideology & ideology \\
votes cast & votes cast & votes cast \\
party performance & party performance & party performance \\
(specific tasks) & (specific tasks) & (specific tasks) \\
retro. eval. party & seg. party ID & party thermometer \\
demographics & demographics & demographics \\
seg. party ID & party thermometer & retro. eval. party \\
& & \\
\hline
\end{tabular}

Table 5 presents the results of a loglinear analysis similar to the one employed in the previous section. Here the crosstabulations to be analyzed are the three measures of federally segmented party identification and the three counterpart segmented measures of retrospective evaluations by question order. As in the previous section, each row indicates whether the null hypothesis -- i.e., that question order has no effect (formally, no interaction term is present in the model) -- can be accepted. If the null hypothesis is accepted, then, regardless of when asked in the survey, no statistically significant variation in the distribution of partisanship, as measured by federally segmented identification and retrospective evaluation items, exists in these data. Table 5 indicates that in five of six instances, the null hypothesis can be accepted at the customary .05 level. Only in considering 
local retrospective evaluations does question order have a significant effect.

Table 5. A Loglinear Analysis of Consistency Effects on Multiple Measures of Partisanship

\begin{tabular}{|c|c|c|}
\hline Partisanship & $\begin{array}{c}\text { Likelihood Ratio } \\
\text { Chi-Square * }\end{array}$ & $\mathrm{N}$ \\
\hline \multicolumn{3}{|c|}{ Segmented Partisanship } \\
\hline National & .870 & 569 \\
\hline State & .726 & 565 \\
\hline Local & .274 & 559 \\
\hline \multicolumn{3}{|c|}{ Retrospective Evaluation } \\
\hline National & .994 & 567 \\
\hline State & .089 & 560 \\
\hline Local & .022 & 557 \\
\hline
\end{tabular}

${ }^{*} \mathrm{p} \leq .05$

Moreover, an examination of the standardized residuals reveals that significant deviation occurs when local retrospective evaluations are solicited at the beginning or at the very end of the questionnaire, in formats 2 and 3 . There is no significant deviation owing to format 1 , when evaluations are asked in the middle of the survey.

We can test the same hypothesis on the partisan thermometer questions using one-way analysis of variance. The results of this analysis are shown in Table 6. For Republicans and Democrats, the placement of the thermometer questions within the survey has no effect on the ratings received. However, the ratings of

Table 6. ANOVA Results of Consistency Effects on Thermometer Ratings of Partisan Groups

\begin{tabular}{lcccc}
\hline & \multicolumn{2}{c}{ Questionnaire Position } & F prob \\
\cline { 2 - 4 } & First & Last & Middle & \\
Republicans & 51.98 & 54.05 & 55.81 & .739 \\
$\mathrm{~N}=$ & 186 & 196 & 185 & \\
Democrats & 52.83 & 54.47 & 54.01 & .159 \\
$\mathrm{~N}=$ & 185 & 196 & 185 & \\
Independents & & & & \\
$\mathrm{N}=$ & 29.77 & 36.15 & 41.86 & .000 \\
\hline
\end{tabular}

Independents are significantly affected by the positioning of thermometer questions in the survey. In particular, a Sheffe test indicates that significant inter-group 
variation exists between the first and the third groups; that is, between ratings received when the thermometer questions were asked at the top of the survey and those received when these items appeared near the middle of the questionnaire. All in all, question order mattered in only two of the nine comparisons. Let us now look more closely at those two instances.

In both instances, a frame-of-reference explanation helps us to understand our results, but particularly those results regarding the thermometer questions. Independents do not form as identifiable a group as Republicans and Democrats, if only because the latter have formal party structures at all levels of government and are formally represented in the executive and legislative branches and in the judiciary in many states and locales. The referents for Republicans and Democrats are considerably more concrete than for Independents, folklore about voting for the candidate rather than the party notwithstanding. Moreover, the referents for Independents vary a great deal not only in their ballot-consistency (frequency of availability as a choice), but may vary greatly in program and personification (e.g., Wallace to Anderson to Perot), as well. Hence, it is perfectly reasonable to expect that evaluations of Republicans and Democrats would be least susceptible and evaluations of Independents most susceptible to frame of reference effects.

Salience, consistency and other effects can have less of an impact on thermometer measurements because there is no significant difference between the results of format 2 and either format 1 or format 3 . The thermometer questions are last in format 2 , and, thus, are subject to effect by all of the preceding variables.

It is questionable whether salience effects reasonably can explain the differences uncovered for local retrospective evaluations because of the lack of effect in format 1 , where retrospective evaluations follow the questions most likely to be involved in such an effect: ideology, voting behavior, party performance, issue preferences, etc. Nor is response fatigue a satisfactory explanation, because neither evaluations of national parties nor of state parties are affected in the same way as evaluations of local parties, and these questions were asked as a bloc in each form.

However, there may be a consistency effect explanation, because in questionnaire form 3 the segmented identification questions preceded retrospective evaluations for the first time. Because local retrospective evaluations are the only ones affected by question form, specific hypotheses can be generated: namely, the null hypothesis of no interaction between retrospective evaluation and segmented partisanship should be accepted for national and state evaluations but rejected for local evaluations. The question order variable will be omitted from all three calculations, but the thermometer variables will be included as covariates since they are common precedents to the retrospective questions in both forms. The dependent variable frequencies to be explained are generated from the crosstabulation of retrospective evaluation by segmented partisanship by question order. Table 7 presents the results of this analysis.

As anticipated, the likelihood ratio chi-squares call for acceptance of the null 
hypothesis for national and state retrospective evaluations, but for rejection in the case of local retrospective evaluations. Thus, the dependent crosstabulation reduces to retrospective evaluations by question order for national and state retrospections, tables already evaluated for the null hypothesis above.

Table 7. Loglinear Analysis of the Consistency Effects of Segmented Partisanship Measures on Retrospective Evaluation

\begin{tabular}{llcr}
\hline $\begin{array}{l}\text { Retrospective } \\
\text { Measure }\end{array}$ & $\begin{array}{c}\text { Omitted Seg. Partisan } \\
\text { Interaction }\end{array}$ & $\begin{array}{c}\text { Likelihood Ratio } \\
\text { Chi-Square* }\end{array}$ & N \\
\hline National & National ID & .187 & 494 \\
State & State ID & .172 & 490 \\
Local & Local ID & .000 & 481 \\
\hline
\end{tabular}

${ }^{*} \mathrm{p} \leq .05$

For local retrospective evaluations on the other hand, the dependent crosstabulation includes segmented partisan identification. The loglinear coefficients in Table 8 , corresponding to the lambda parameters produced by logit analysis or logistic regression, can be used to assess the effects of segmented party

Table 8. Loglinear Parameter Estimates for Local Retrospective Evaluations

$\begin{array}{lcc}\text { Local Retroactive Evalavation } & -2.74 & -.61 \\ & -7.37 & -1.25 \\ \text { Local Retroactive Evaluation } & -.28 & -.39 \\ \text { by Local Party Identification } & .00 & .01 \\ & .72 & 1.26 \\ & .73 & 2.29 \\ \text { Local Retroactive Evaluation } & .01 & .31 \\ \text { by Republican Thermometer } & .10 & 2.13 \\ \text { Local Retroactive Evaluation } & & 1.04 \\ \text { by Democratic Thermometer } & .06 & .04 \\ & .00 & -1.57 \\ \text { Local Retroactive Evaluation } & & 2.01 \\ \text { by Independent Thermometer } & -.03 & \\ & .03 & \\ \text { N = 481 } & & \end{array}$

*The category of contrast is "Republican" in each implied table above. Thus, the two-entry blocs refer to Democrat and Independent (or "no difference") contrasts to Republican. The four-entry bloc corresponds to the 1,$1 ; 1,2 ; 2,1$ and 2,2 cells, respectively, of the $3 \times 3$ table created by cross-tabulating local retrospective evaluations (Democrat, no difference, and Republican) with local party identification (Democrat, Independent, and Republican). The cells falling in row and column 3 form the omitted Republican contrasts. 
identification and group thermometer ratings on local retrospective evaluations (Demaris 1992). The Z-probability values identify where local partisan identification has a significant impact on retrospective evaluations: local Independent and Republican identities affect local retrospective evaluations insofar as the "no difference" and "Republican" response-categories are concerned, respectively. This result is perfectly paralleled by the pattern of $Z$-values and corresponding lambda coefficients for thermometer ratings elsewhere in the table. No analogous effect is registered by segmented Democratic partisanship or the Democratic thermometer on the Democrat response-category or any other partition.

In addition to frame of reference effects, then, part of the reason that question order affects local retrospective evaluations is due to a "strain for consistency" with local partisanship and with thermometer ratings of Republicans and Independents. This result may have broader application to theorizing about segmented partisanship. Contrary to these findings of a strain toward consistency, Arkansas encouraged volatility of partisan identification. This speculation received empirical support from the fact that Republicans and Independents are more likely to be segmented, not global, partisans in this modified, one-party state (Maggiotto and Wekkin 1987, 1989). That research did not include an examination of retrospective evaluations. These results may highlight, therefore, the true multidimensionality of segmented partisanship through the conceptually separate, but not always statistically independent, measures of group affinity (thermometers), retrospective evaluations, and partisan identification.

An alternative explanation reflects the dearth of Republican candidates at the local level. Lacking obvious referents for local retrospective evaluation, Independent and Republican identifiers may be projecting attitudes (Berelson et at. 1954), thus creating consistency across measures and levels artificially. We must recall that even in 1980, when Ronald Reagan handily defeated Jimmy Carter statewide and Republicans won the governorship and two of four congressional seats in Arkansas, Republicans won only seven contested state legislative seats, two county judgeships, one county sheriff's seat and a dozen Quorum Court positions across the state's 75 counties (Wekkin et al. 1987). Similarly, in the 1986 general election, the Arkansas GOP contested only 131 municipal and county races, winning but 29. And, in the Second Congressional District, where our survey was conducted, Republicans fielded candidates for a mere 16 municipal and county races, winning only two (Arkansas Democrat 6 November 1986).

\section{Conclusion}

Contrary to received wisdom, responses to national party identification questions do not structure responses to state (or, inferentially, to local) party identification questions, when such items are used to measure multiple party identification. The absence of question order effects during the first experiment suggests that it is not necessary for studies of multiple partisanship to control for 
such effects by rotating the sequence of national, state, and local party identification items.

More generally, contrary to what Sears and Lau and most other students of question order give us to expect under conditions of proximity, interrelatedness, and subjectivity, question order effects generally do not contaminate the responses volunteered to partisan measures when more than one operationalization is used to assess the various dimensions of partisanship. Thermometer ratings of independents and retrospective evaluations of local government were the only measures contaminated. Moreover, only one of these -- local retrospective evaluations -- was constrained significantly by another partisan measure. This distortion easily is accommodated and, thus, should not be problematic in future analysis, especially if either of the two hypotheses offered to explain the effect is substantiated. Although a simple and effective method of controlling for contamination, systematic rotation of the sequence of related measures, such as was implemented during the second experiment, does not appear necessary.

\section{NOTES}

The authors gratefully acknowledge the support of this research by generous grants from the University Research Council of the University of Central Arkansas and the Faculty Research Committee of Bowling Green State University. Neither of these agencies is responsible for the conclusions drawn or for any errors found below.

'Arkansas' Second District is a mixed urban/rural district that occupies the geographic center of the state and includes most of the Greater Little Rock SMSA.

${ }^{2}$ The exact wording of the partisan identification item was:

Thinking now only of national politics, do you usually consider yourself to be a Republican, a Democrat, an Independent, or what? . . [contingencies].

Thinking now only of state politics here in Arkansas, do you usually consider yourself to be a Republican, a Democrat, an Independent, or what? . . [contingencies].

Thinking now only of local politics here in your community, do you usually think of yourself to be a Republican, a Democrat, an Independent or what? ...[contingencies].

\section{APPENDIX}

The exact wording and order of the questions in questionnaire format 1 of the 1988 survey was as follows (response categories are omitted to save space):

Below is a "political thermometer" to test your feelings about certain groups. Its temperature runs from 100 degrees, which means you have very warm, positive feelings toward a group, to 0 degrees, which means you feel very cool toward a group. A temperature of about 50 degrees would mean you have neutral feelings toward a group.

1.Where would you place your feelings toward the Republican party on this thermometer? 
2. Where would you place your feelings toward the Democratic party on this thermometer?

3. Where would you place your feelings toward Independents on this thermometer?

4.Regardless of the party you favor, on most political matters do you usually consider yourself to be a liberal, a moderate, or a conservative?

5.In the presidential primary held today, who did you vote for?

6. Why did you vote for that candidate?

7.Who do you intend to vote for in the presidential election in November? (Assume the candidate you support is running then).

8.Who do you think will actually win the Democratic nomination?

9.Who do you think will actually win the Republican nomination?

10. Of the two presidential candidates you predict will be running against each other in November, which would you vote for to be president?

11. In you opinion, which political party usually does the best job of maintaining friendly relations with foreign nations?

12. In your opinion, which political party usually does the best job of dealing with the nation's social problems?

13. In your opinion, which political party usually does the best job of managing the nation's economy?

14. In your opinion, which political party usually does the best job of controlling wasteful government spending?

15. In your opinion, which political party usually does the best job of dealing with foreign threats to American interest?

16. In your opinion, which political party usually does the most for Arkansas?

17. All in all, which political party usually does the best job of governing the United States?

18. All in all, which political party usually does the best job of governing Arkansas?

19. All in all, which political party usually does the best job of governing your local community?

20-26. (Standard demographic questions)

27. Thinking now only of national politics, do you usually consider yourself to be a Republican, Democrat, Independent, or what? . . .(standard NES probes for intensity and leaning)

28. Thinking now only of state politics here in Arkansas, do you usually consider yourself to be a Republican, Democrat, Independent, or what? ... (same probes)

29.Thinking now only of local politics here in your community, do you usually consider yourself to be a Republican, a Democrat, an Independent, or what? . . (same probes)

In Table 4, format 2, question-items 1-3 (thermometer-items and preceding instruction) were relocated to positions 27-29; items 27-29 (multiple partisanship items) were relocated to positions 17-19; and items 17-19 (retrospective evaluation items) were relocated to positions 1-3.

In Table 4, format 3, the thermometer-items moved again to positions 17-19; the multiple partis anship items moved to positions 1-3; and the retrospective evaluation items moved to positions 27-29. 


\section{REFERENCES}

Abramson, Paul R., Brian D. Silver, and Barbara Anderson. 1987. The Effects of Question Order in Attitude Surveys: The Case of the SRC/CPS Citizen Duty Items. American Journal of Political Science 31: 900-908.

Berelson, Bernard R., Paul F. Lazarsfeld and William N. McPhee. 1954. Voting: A Study of Opinion Formation in a Presidential Campaign. Chicago: University of Chicago Press.

Bishop, George F. 1990. Issue Involvement and Response Effects in Public Opinion Surveys. Public Opinion Quarterly 54: 209-218.

Bishop, George F., Robert W. Oldendick, and Alfred J. Tuchfarber. 1982. Political Information Processing: Question Order and Context Effects. Political Behavior 4: $177-200$.

- 1984. Interest in Political Campaigns: The Influence of Question Order Electoral Context. Political Behavior 6: 159-169.

Campbell, Angus, Philip E. Converse, Warren E. Miller, and Donald E. Stokes. 1960. The American Voter. New York: John Wiley \& Sons.

Demaris, Alfred. 1992. Logit Modeling:PracticalApplications. Newbury Park, CA: Sage Publications.

Feinberg, Stephen E. 1977. The Analysis of Cross-Classified Categorical Data. Cambridge: MIT Press.

Fiorina, Morris P. 1981. Restrospective Voting in American National Election. New Haven: Yale University Press.

Franklin, Charles F. 1984. Issue Preferences, Socialization, and the Evolution of Party Identification. American Journal of Politics 28: 459-478.

Franklin, Charles F. and John E. Jackson. 1983. The Dynamics of Party Identification. American Political Science Review 77:957-973.

Hadley, Charles D. 1985. Dual Partisan Identification in the South. Journal of Politics 47: 254-268.

Jennings, M. Kent and Richard G. Niemi. 1966. Party Identification at Multiple Levels of Government. American Journal of Sociology 72: 86-101.

Katz, Richard J. 1979. The Dimensionality of Partisan Identification: Cross-National Perspectives. Comparative Politics 11: 147-163.

Lau, Richard R., David O. Sears, and Tom Jessor. 1990. Fact or Artifact Revisited: Survey Instrument Effects and Pocketbook Politics. Political Behavior 12: 217-240.

Lewis-Beck, Michael. 1985. Pocketbook Voting in U.S. National Election Studies: Fact or Artifact? American Journal of Political Science 29: 348-356.

Maggiotto, Michael A. 1986. Party Identification in the Federal System. Paper delivered at the annual meeting of the American Political Science Association, Washington, DC.

Maggiotto, Michael A. and James E. Piereson. 1977. Partisan Identification and Electoral Choice: The Hostility Hypothesis. American Journal of Political Science 21: 745-767.

Maggiotto, Michael A. and Gary D. Wekkin. 1987. Global Concepts and Segmented Partisans: Rejoining Theory and Data. Paper Delivered at the annual meeting of the Southwestern Political Science Association meeting, Dallas, TX. 
1989. Segmented Partisanship in the Electoral Context. Paper delivered at the annual meeting of the Midwestern Political Science Association, Chicago, IL.

Markus, Gregory B. and Philip E. Converse. 1979. A Dynamic Simultaneous Equation

Model of Electoral Choice. American Political Science Review 73: 1055-1070.

Niemi, Richard G., Stephen Wright, and Lynda W. Powell. 1987. Multiple Party

Identifiers and the Measurement of Party Identification. Journal of Politics 49: 1093-1103.

Page, Benjamin I. and Calvin C. Jones. 1979. Reciprocal Effects of Policy Preferences, Party Loyalties and the Vote. American Political Science Review 73: 1071-1089.

Petrocik, John R. 1974. An Analysis of Intransitivities in the Index of Party Identification.

Political Methodology 1: 31-49.

Sears, David O. and Richard R. Lau. 1983. Inducing Apparently Self-Interested Political

Preferences. American Journal of Political Science 27: 223-252.

Schuman, Howard and Stanley Presser. 1981. Questions and Answers in Attitude Surveys.

New York: Academic Press.

Valentine, David C. and John R. Van Wingen. 1980. Partisanlship, Independence, and

Partisan Identification. American Politics Quarterly 8: 165-186.

Weisberg, Herbert F. 1980. A Multidimensional Conceptualization of Party Identification.

Political Behavior 2:33-60.

Wekkin, Gary D. 1991. Why Crossover Voters Are Not "Mischievous Voters": The Segmented Partisanship Hypothesis. American Politics Quarterly 19: 229-247.

, Michael A. Maggiotto, and Shannon G. Davis. 1987. Party Identification and Partisan Realignment in Arkansas. Comparative State Politics 8 (October): 811. 